\title{
OPEN Ni-citric acid coordination polymer as a practical catalyst for multicomponent reactions
}

\author{
Mostafa Koolivand ${ }^{1}$, Mohsen Nikoorazm ${ }^{1 凶}$, Arash Ghorbani-Choghamarani ${ }^{2 凶}$, \\ Reza Azadbakht ${ }^{2}$ \& Bahman Tahmasbi ${ }^{1}$
}

Coordinative polymers (CP) are a subclass of Metal-organic frameworks (MOFs) with porous microstructures which have been widely synthesized in recent years and applied in various fields especially in catalysis science. In this work Coordinative polymers (CP) of nickel and citric acid (CA) was prepared as a new catalyst ( $\mathrm{Ni}-\mathrm{CP}$ ) and applied in organic multicomponent reactions. The obtained catalyst was characterized by SEM, WDX, EDS, AAS, FT-IR, XRD and BET analysis. $\mathrm{N}_{2}$ adsorptiondesorption isotherms indicate good BET surface area for $\mathrm{Ni}-\mathrm{CP}$; therefore can be employed as an efficient catalyst in multicomponent reactions for the synthesis of polyhydroquinoline and 2,3-dihydroquinazolin-4(1H)-one derivatives. Finally, this catalyst was recovered and reused several consecutive times.

Multicomponent reactions (MCRs) have gained more attention in the last decade as a great and powerful strategy in the synthesis of natural products, medicinal chemistry and organic reactions ${ }^{1-11}$. Typically, MCRs are defined as one-pot reactions with more than two starting materials join to generate a desired single product of the reagent atoms $^{1,12}$. Comparison to multistep reactions, MCRs offer a high atom economy, simple procedures, selectivity, environmental friendliness, time and energy saving ${ }^{8,9,13}$. In this regard various heterogeneous and homogeneous (Transition metals, transition metal complexes or supported metals) catalysts are employed in MCRs to increase selectivity and rate of the reaction ${ }^{4,14}$. For example, multicomponent reactions have been significantly extended using Coordinative polymers $(\mathrm{CP})^{15}$. Coordinative polymers are commonly formed by transition metal ions and an organic multi-dentate ligand ${ }^{15,16}$. CP platforms with unique properties such as easy recoverability, large pore aperture, low density, high specific surface area, permanent nanoscale porosity and uniform structured cavities, have been used as ideal catalysts in MCRs and other applications such as drug delivery, gas storage, separation science, gas purification, sensing, optoelectronics, magnetism and luminescence ${ }^{17-22}$. In the continuation of the development of new CP catalysis in MCRs. Herein we report the synthesis of a new CP of nickel and citric acid and its catalytic activity in the synthesis of polyhydroquinoline and 2,3-dihydroquinazolin-4(1H)-one derivatives. Polyhydroquinolines and 2,3-dihydroquinazolin- $4(1 \mathrm{H})$-ones have a wide range of biological properties and pharmaceutical activities ${ }^{23-28}$. For example, nifedipine, amlodipine and nicardipine are several biologically active compounds of polyhydroquinoline derivative ${ }^{29,30}$. Besides, 2, 3-Dihydroquinazolin- $4(1 \mathrm{H})$ ones are known to possess diverse pharmacological actions ${ }^{31,32}$. For example, quinethazone, fenquizone, metolazone, evodiamine, afloqualone, methaqualone are several biologically active compounds of 2,3-dihydroquinazolin- $4(1 \mathrm{H})$-one derivatives ${ }^{33-35}$. Also, 2-(2-hydroxy-phenyl)-4(3H)-quinazolinone (HPQ) was utilized in the detection of metal ions or act as a biosensor to scrutinize the Monoamine oxidases activity ${ }^{36-39}$.

\section{Experimental}

Materials and instruments. All chemicals and solvents employed in this work were purchased from Aldrich or Merck companies and used without further purification.

Preparation of Ni-CP. To prepare Ni-CP, citric acid ( $1 \mathrm{mmol})$ was dissolved in water $(2 \mathrm{~mL})$ and, then, it was added to a solution of DMF $(12 \mathrm{~mL})$ containing $2 \mathrm{mmol}$ of nickel nitrate. Afterward, the obtained mixture was transferred into a autoclave and heated at $160^{\circ} \mathrm{C}$ for 1 day, which then cooled down and Subsequently washed with ethyl acetate. Finally, the Ni-CP product was dried at $60^{\circ} \mathrm{C}$ in an oven (Fig. 1).

${ }^{1}$ Department of Chemistry, Faculty of Science, Ilam University, P. O. Box 69315516, Ilam, Iran. ${ }^{2}$ Department of Organic Chemistry, Faculty of Chemistry, Bu-Ali Sina University, 6517838683 Hamedan, Iran. ${ }^{\square}$ email: m.nikorazm@ilam.ac.ir; a.ghorbani@basu.ac.ir 


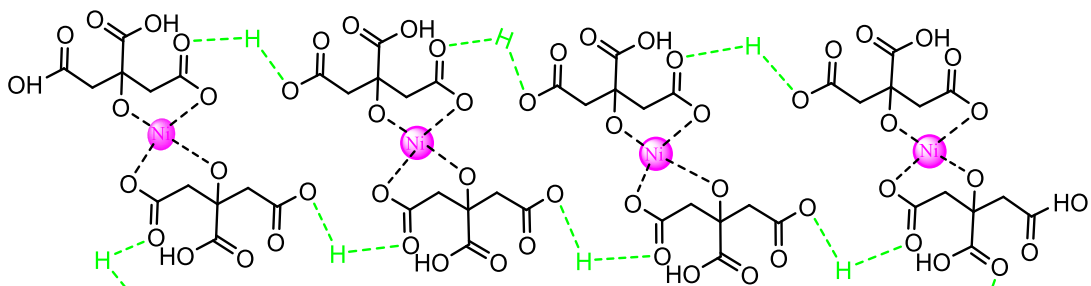

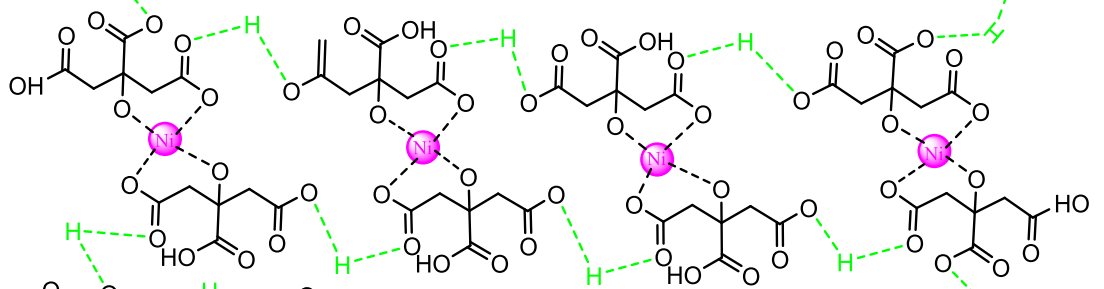

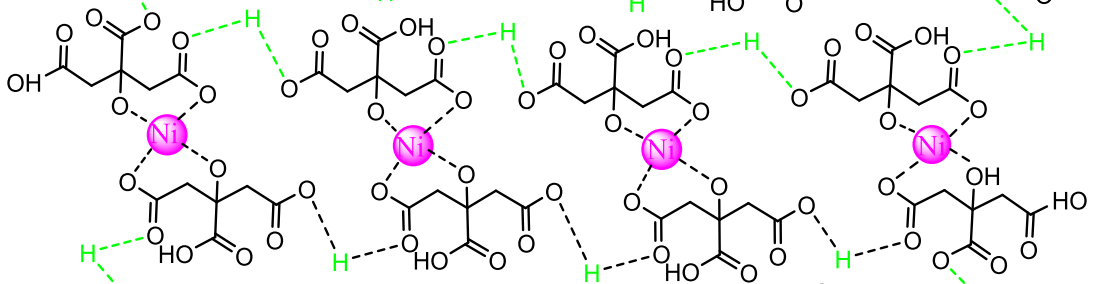

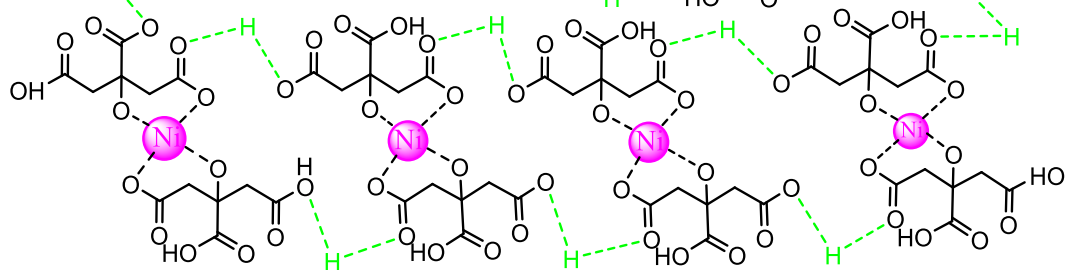

Figure 1. The topological structure of Ni-CP.

General procedure for the synthesis of polyhydroquinoline in the presence of $\mathrm{Ni}-\mathrm{CP}$. A mixture of various aromatic aldehydes $(1 \mathrm{mmol}), \mathrm{NH}_{4} \mathrm{OAc}(1 \mathrm{mmol})$, dimedone $(1 \mathrm{mmol})$, ethyl acetoacetate $(1 \mathrm{mmol})$, and $\mathrm{Ni}-\mathrm{CP}(5 \mathrm{mg})$, was refluxed in ethanol at $80^{\circ} \mathrm{C}$. Completion of the following reaction has been analyzed via TLC, Subsequent the reaction mixture was diluted with hot ethanol to dissolve the organic products, the catalyst was separated using simple filtration and the resultant unrefined solid products, was further purified through recrystallization in ethanol and dried to obtain a pure solid.

General procedure for the synthesis of 2,3-dihydroquinazolin-4(1H)-ones in the presence of $\mathrm{Ni}$-CP. A mixture of various aromatic aldehydes $(1 \mathrm{mmol})$, anthranilamide $(1 \mathrm{mmol})$ and $\mathrm{Ni}-\mathrm{CP}(6 \mathrm{mg})$, was refluxed in ethanol at $80^{\circ} \mathrm{C}$. Completion of the following reaction has been analyzed via TLC, Subsequent the reaction mixture was diluted with hot ethanol to dissolve the organic products, the catalyst was separated using simple filtration and the resultant unrefined solid products, was further purified through recrystallization in ethanol and dried to obtain a pure solid.

Selected spectral data. 2-(4-Methoxyphenyl)-2,3-dihydroquinazolin-4(1H)-one (Table 5, entry 4). ${ }^{1} \mathrm{H}$ $\operatorname{NMR}\left(400 \mathrm{MHz}, \mathrm{CDCl}_{3}\right): \delta_{\mathrm{H}}=8.18(\mathrm{~s}, 1 \mathrm{H}), 7.62-7.60(\mathrm{~d}, J=8 \mathrm{~Hz}, 1 \mathrm{H}), 7.42-7.41(\mathrm{~d}, J=4 \mathrm{~Hz}, 2 \mathrm{H}), 7.25-7.22(\mathrm{t}$, $J=8 \mathrm{~Hz}, 1 \mathrm{H}), 7.00(\mathrm{br}, 1 \mathrm{H}), 6.95-6.93(\mathrm{~d}, J=8 \mathrm{~Hz}, 2 \mathrm{H}), 6.75-6.73(\mathrm{~d}, J=8 \mathrm{~Hz}, 1 \mathrm{H}), 6.68-6.65(\mathrm{t}, J=8 \mathrm{~Hz}, 1 \mathrm{H})$, $5.70(\mathrm{~s}, 1 \mathrm{H}), 3.74(\mathrm{~s}, 3 \mathrm{H}) \mathrm{ppm}$.

2-(p-tolyl)-2,3-Dihydroquinazolin-4(1H)-one (Table 5, entry 3). ${ }^{1} \mathrm{H} \mathrm{NMR}\left(400 \mathrm{MHz}, \mathrm{CDCl}_{3}\right): \delta_{\mathrm{H}}=8.23(\mathrm{~s}, 1 \mathrm{H})$, 7.63-7.61 (d, $J=8 \mathrm{~Hz}, 1 \mathrm{H}), 7.39-7.37(\mathrm{~d}, J=4 \mathrm{~Hz}, 2 \mathrm{H}), 7.25-7.22(\mathrm{t}, J=4 \mathrm{~Hz}, 1 \mathrm{H}), 7.19-7.18(\mathrm{~d}, J=4 \mathrm{~Hz}, 1 \mathrm{H})$, $7.05(\mathrm{~s}, 1 \mathrm{H}), 6.76-6.74(\mathrm{~d}, J=8 \mathrm{~Hz}, 1 \mathrm{H}), 6.69-6.65(\mathrm{t}, J=8 \mathrm{~Hz}, 1 \mathrm{H}), 5.72(\mathrm{~s}, 1 \mathrm{H}), 2.29(\mathrm{~s}, 3 \mathrm{H}) \mathrm{ppm}$.

2-Phenyl-2,3-Dihydroquinazolin-4(1H)-one (Table 5, entry 1). ${ }^{1} \mathrm{H}$ NMR $\left(400 \mathrm{MHz}, \mathrm{CDCl}_{3}\right): \delta_{\mathrm{H}}=8.27(\mathrm{~s}, 1 \mathrm{H})$, $7.62-7.60(\mathrm{~d}, J=8 \mathrm{~Hz}, 1 \mathrm{H}), 7.50-7.48(\mathrm{~d}, J=4 \mathrm{~Hz}, 2 \mathrm{H}), 7.40-7.34(\mathrm{~m}, 3 \mathrm{H}), 7.25-7.22(\mathrm{t}, J=8 \mathrm{~Hz}, 1 \mathrm{H}), 7.10(\mathrm{~s}$, $1 \mathrm{H}), 6.75-6.74(\mathrm{~d}, J=4 \mathrm{~Hz}, 1 \mathrm{H}), 6.68-6.65(\mathrm{t}, J=8 \mathrm{~Hz}, 1 \mathrm{H}), 5.75(\mathrm{~s}, 1 \mathrm{H}) \mathrm{ppm}$.

Ethyl 2,7,7-trimethyl-4-(3-nitrophenyl)-5-oxo-1,4,5,6,7,8-hexahydroquinoline-3-carboxylate (Table 3, entry 8). ${ }^{1} \mathrm{H} \mathrm{NMR}\left(400 \mathrm{MHz}, \mathrm{CDCl}_{3}\right): \delta_{\mathrm{H}}=9.24(\mathrm{~s}, 1 \mathrm{H}), 7.97(\mathrm{~s}, 2 \mathrm{H}), 7.61-7.51(\mathrm{~d}, J=40 \mathrm{~Hz}, 2 \mathrm{H}), 4.96(\mathrm{~s}, 1 \mathrm{H}), 3.96$ (s, 2H), 2.50-2.43 (m, 2H), $2.33(\mathrm{~s}, 3 \mathrm{H}), 2.20-2.17(\mathrm{~d}, J=12 \mathrm{~Hz}, 1 \mathrm{H}), 1.99-1.96(\mathrm{~d}, J=12 \mathrm{~Hz}, 1 \mathrm{H}), 1.12-1.09$ (t, $J=8 \mathrm{~Hz}, 3 \mathrm{H}), 1.00(\mathrm{~s}, 3 \mathrm{H}), 0.82(\mathrm{~s}, 3 \mathrm{H}) \mathrm{ppm}$. 

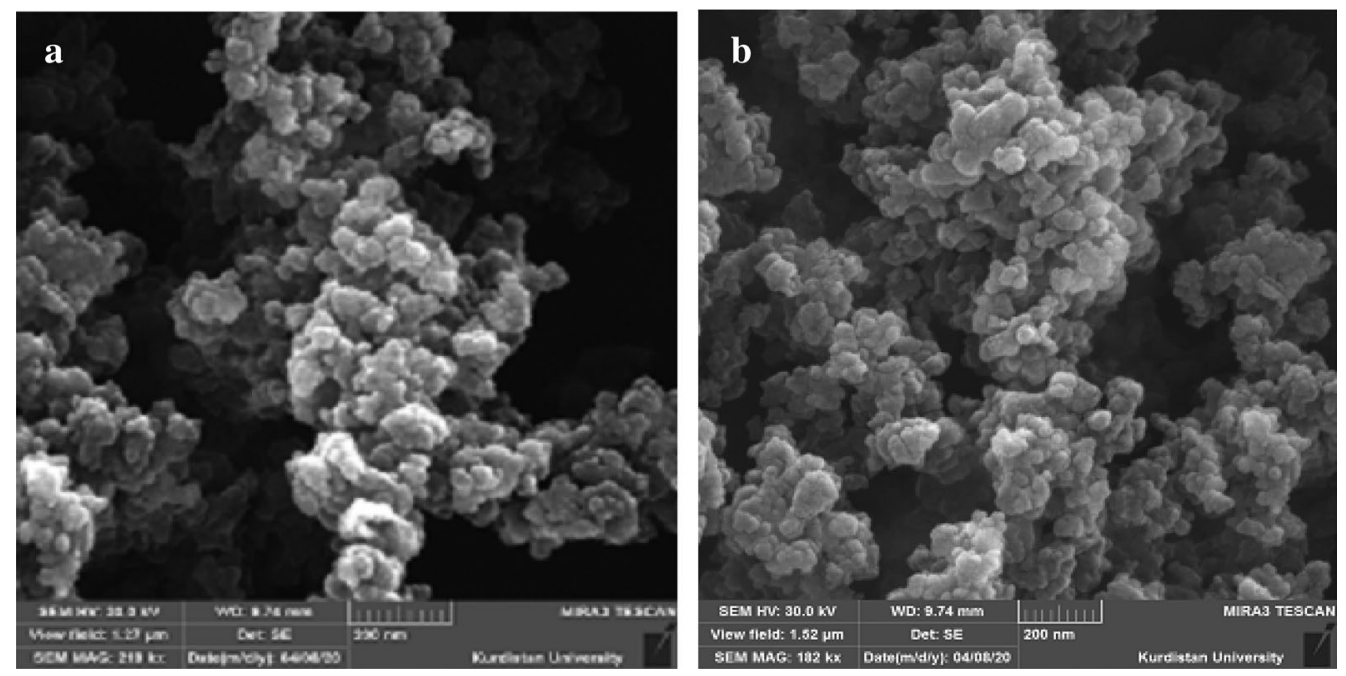

Figure 2. SEM images of Ni-CP.

Ethyl 4-(4-methoxyphenyl)-2,7,7-trimethyl-5-oxo-1,4,5,6,7,8-hexahydroquinoline-3-carboxylate (Table 3, entry 3). ${ }^{1} \mathrm{H}$ NMR $\left(400 \mathrm{MHz}, \mathrm{CDCl}_{3}\right): \delta_{\mathrm{H}}=9.00(\mathrm{~s}, 1 \mathrm{H}), 7.05-7.03(\mathrm{~d}, J=8 \mathrm{~Hz}, 2 \mathrm{H}), 6.74-6.72(\mathrm{~d}, J=8 \mathrm{~Hz}, 2 \mathrm{H}), 4.78$ $(\mathrm{s}, 1 \mathrm{H}), 3.97-3.95(\mathrm{~d}, J=8 \mathrm{~Hz}, 2 \mathrm{H}), 3.66(\mathrm{~s}, 3 \mathrm{H}), 2.49(\mathrm{~s}, 2 \mathrm{H}), 2.26(\mathrm{~s}, 3 \mathrm{H}), 2.16-2.13(\mathrm{~d}, J=12 \mathrm{~Hz}, 1 \mathrm{H}), 1.98-1.94$ $(\mathrm{d}, J=16 \mathrm{~Hz}, 1 \mathrm{H}), 1.14-1.11(\mathrm{t}, J=8 \mathrm{~Hz}, 3 \mathrm{H}), 1.00(\mathrm{~s}, 3 \mathrm{H}), 0.88(\mathrm{~s}, 3 \mathrm{H}) \mathrm{ppm}$.

\section{Result and discussion}

Herein coordination polymer of nickel and Citric acid (Ni-CP) is reported as an efficient catalyst in multicomponent reactions for the synthesis of polyhydroquinoline and 2,3-dihydroquinazolin-4(1H)-one derivatives. Ni-CP was characterized by AAS, EDS, WDX, SEM, TGA, XRD, FT-IR and BET analysis. The surface morphological features of synthesized $\mathrm{Ni}-\mathrm{CP}$ were studied by scanning electron microscope. Figure 2 shows the SEM image of $\mathrm{Ni}-\mathrm{CP}$ with a magnification of 5000 . The instrumental parameters, accelerating voltage, spot size, and magnification and working distances are indicated on the SEM image. The results indicate that mono-dispersive and highly crystalline Ni-CP is obtained. The appearance of some particles is spherical shape. We can observe that the Ni-CP is highly agglomerated and they are essentially cluster of Ni-CP. The SEM picture indicates the size of polycrystalline particles. The observation of some larger Ni-CP may be attributed to the fact that Ni-CP tends to agglomerate due to their high surface energy and high surface tension of the ultrafine Ni-CP. The fine particle size results in a large surface area that in turn, enhances the Ni-CP catalytic activity. So, we can conclude that the prepared $\mathrm{Ni}-\mathrm{CP}$ particles are in the nanometer range. The average diameter of the particle observed from SEM analysis is $30 \mathrm{~nm}$, which is larger than the diameter predicted from X-Ray broadening.

The FT-IR spectrum of the citric acid had absorption bands in the regions of $1703 \mathrm{~cm}^{-1}$ and $1751 \mathrm{~cm}^{-1}$ respectively, which is related to the stretching vibration of the $\mathrm{C}=\mathrm{O}$ bonds of aliphatic carboxylic acid groups (Fig. 3b). These absorption peaks were not observed in the spectra of the prepared Ni-CP, while the spectra of the Ni-CP presented two absorption peaks related to the vibration of the $\mathrm{C}=\mathrm{O}$ bonds of aliphatic carboxylic acid groups at $1589 \mathrm{~cm}^{-1}$. The high shift to the lower wavenumber of the absorption peak of carbonyl demonstrates the existence of the metal coordination bonding and also confirms the complexation reaction between $\mathrm{Ni}$ and citric acid (Fig. 3c). In addition, the peaks at the region of $2855-2928 \mathrm{~cm}^{-1}$ can be regarded as the characteristic of the stretching vibrations of aliphatic $\mathrm{C}-\mathrm{H}^{15}$. The presence of aliphatic $\mathrm{C}-\mathrm{H}$ stretching vibration indicates that the organic ligand used in the final sorbent structure remained and was not destroyed. In addition, various peaks were presented such as $400-1000 \mathrm{~cm}^{-1}$ for $\mathrm{Ni}-\mathrm{O}$ bonds and $3000-3600 \mathrm{~cm}^{-1}$ for OH of carboxylic acid ${ }^{40,41}$. Based on the FT-IR results, we can also observe that the Ni-CP obtained from Nickel Nitrate shows sharp characteristic peaks, suggesting the high crystalline nature of Ni-CP (Fig. 3).

The elemental content of Ni-CP was obtained by EDS (energy-dispersive X-ray spectroscopy) analysis (Fig. 4). Based on the EDS results, the presence of oxygen (A\%:45), carbon (A\%:47), and as well as nickel (A\%:8) species have been confirmed in the structure of the catalyst.

The homogeneous distribution of these elements has been studied by X-Ray Mapping (WDX analysis) in this catalyst which is shown in (Fig. 5). Also, the exact amount of nickel in the structure of this CP catalyst was calculated by atomic absorption spectroscopy (AAS) analysis which was found to be $2.07 \times 10^{-3} \mathrm{~mol} \mathrm{~g}^{-1}$.

To investigate the porous nature and the efficient surface area of Ni-CP, nitrogen adsorption-desorption measurement (BET) was performed. The BET isotherms of Ni-CP and the corresponding Barrett-Joyner-Halenda $(\mathrm{BJH})$ pore size distributions plot are shown in (Fig. 6). As could be seen from this Figure, the observed type$\mathrm{H} 3$ hysteresis loop in the partial pressure range from 0.3 to 1.0 , indicates the slit-shaped pores. The isotherm revealing type- $\mathrm{H} 3$ does not show any limiting adsorption at high $\mathrm{P} / \mathrm{P} 0$, which is observed with spherical in shape particles $^{42}$. Based on BET results, this CP catalyst has a high surface area of about $22.65 \mathrm{~m}^{2} \mathrm{~g}^{-1}$. Also, pore volumes and pore diameters of this CP catalyst are $0.11 \mathrm{~cm}^{3} \mathrm{~g}^{-1}$ and $19.34 \mathrm{~nm}$ respectively. The textural properties of Ni-CP which were obtained from $\mathrm{N}_{2}$ adsorption-desorption analysis are summarized in (Table 1). 


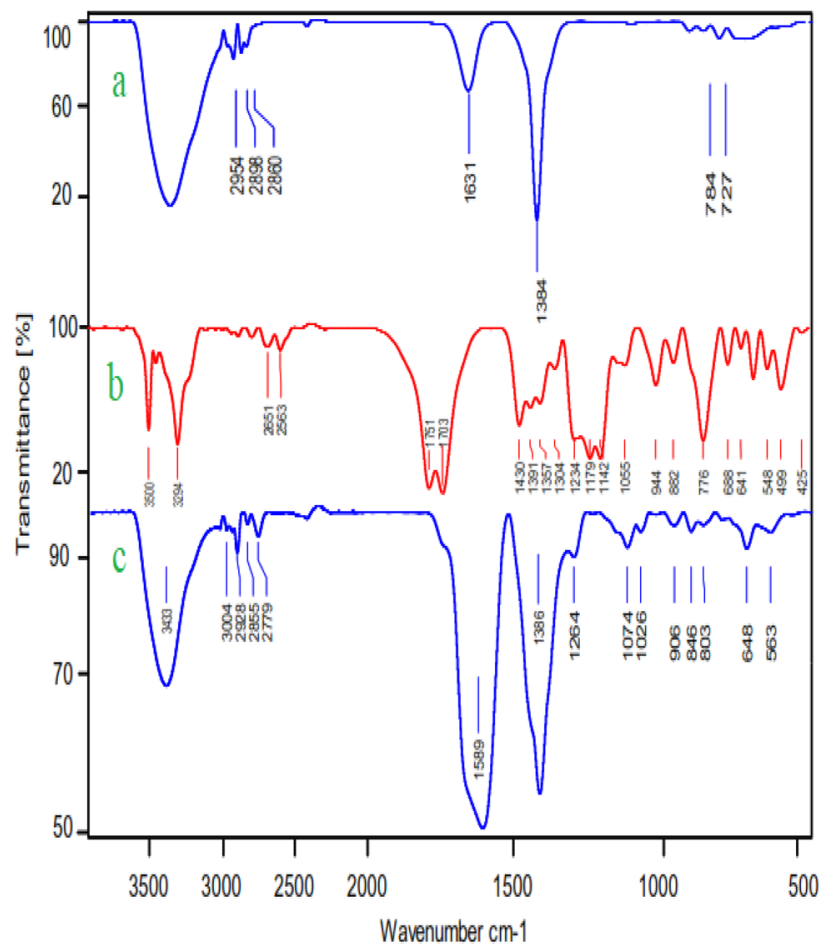

Figure 3. FT-IR Spectrums of (a) Nickel nitrate, (b) citric acid and (c) Ni-CP catalyst.

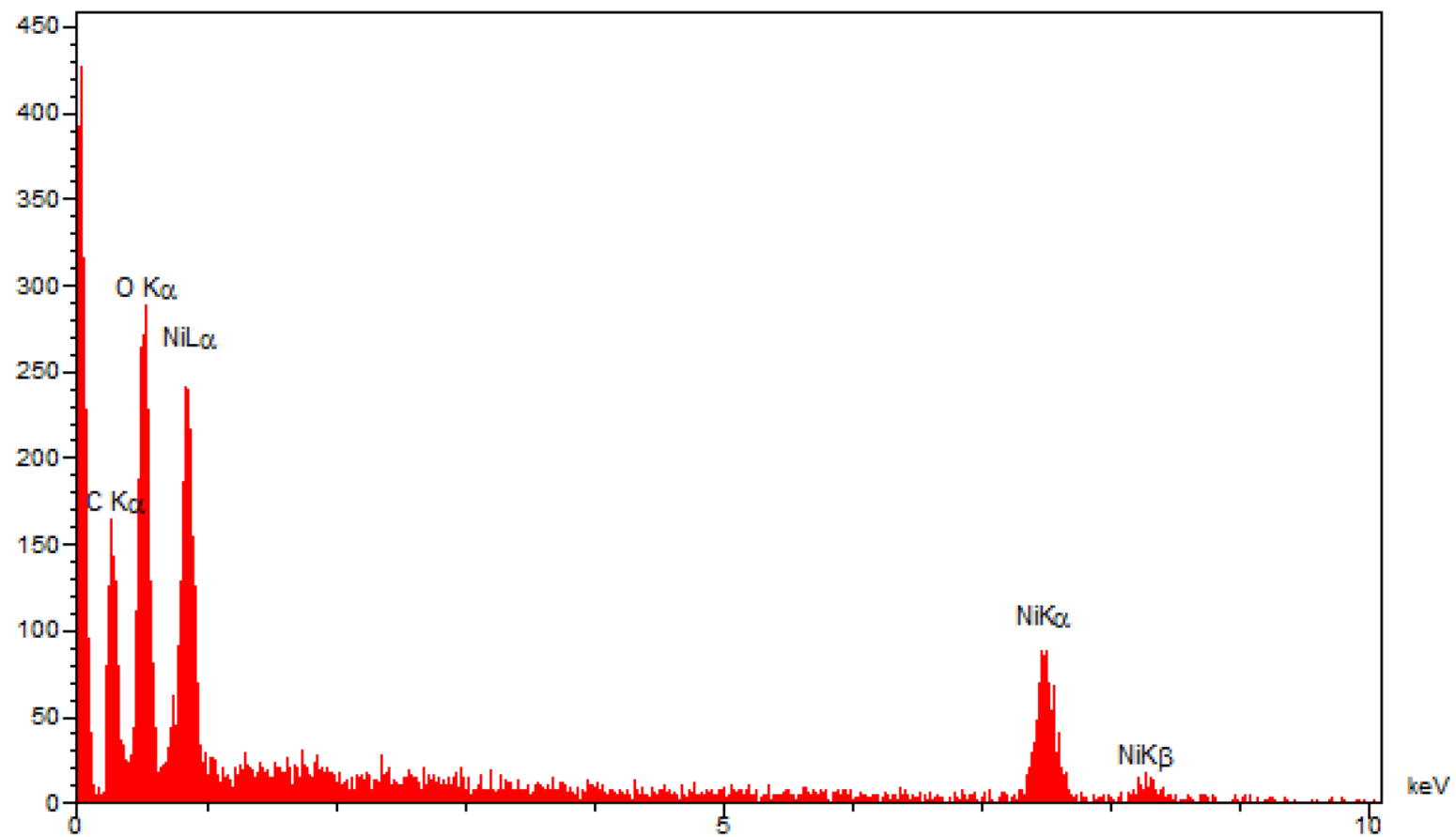

Figure 4. EDS diagram of Ni-CP.

The synthesized CP materials were characterized by PXRD analysis using PW1730 instrument from Philips Company having $\mathrm{CuKa}(\lambda=1.540598 \AA)$ radiation at $40 \mathrm{kV}$ and $30 \mathrm{~mA}$ with $2 \theta=20^{\circ}-100^{\circ}$. The XRD pattern of $\mathrm{Ni}$-CP is shown in (Fig. 7). According to powder PXRD standards (PXRD, Ref. No. 01-087-0718), the crystalline peaks appearing at $42.2^{\circ}, 51.3^{\circ}, 75^{\circ}, 90.3^{\circ}$ can be attributed to the (111), (300), (320), and (350) crystallographic planes of nickel crystals, which are in agreement with the previously reported works of literature ${ }^{43,44}$. The PXRD patterns shown in (Fig. 7) confirm the successful coordination of nickel ions within the prepared framework. 


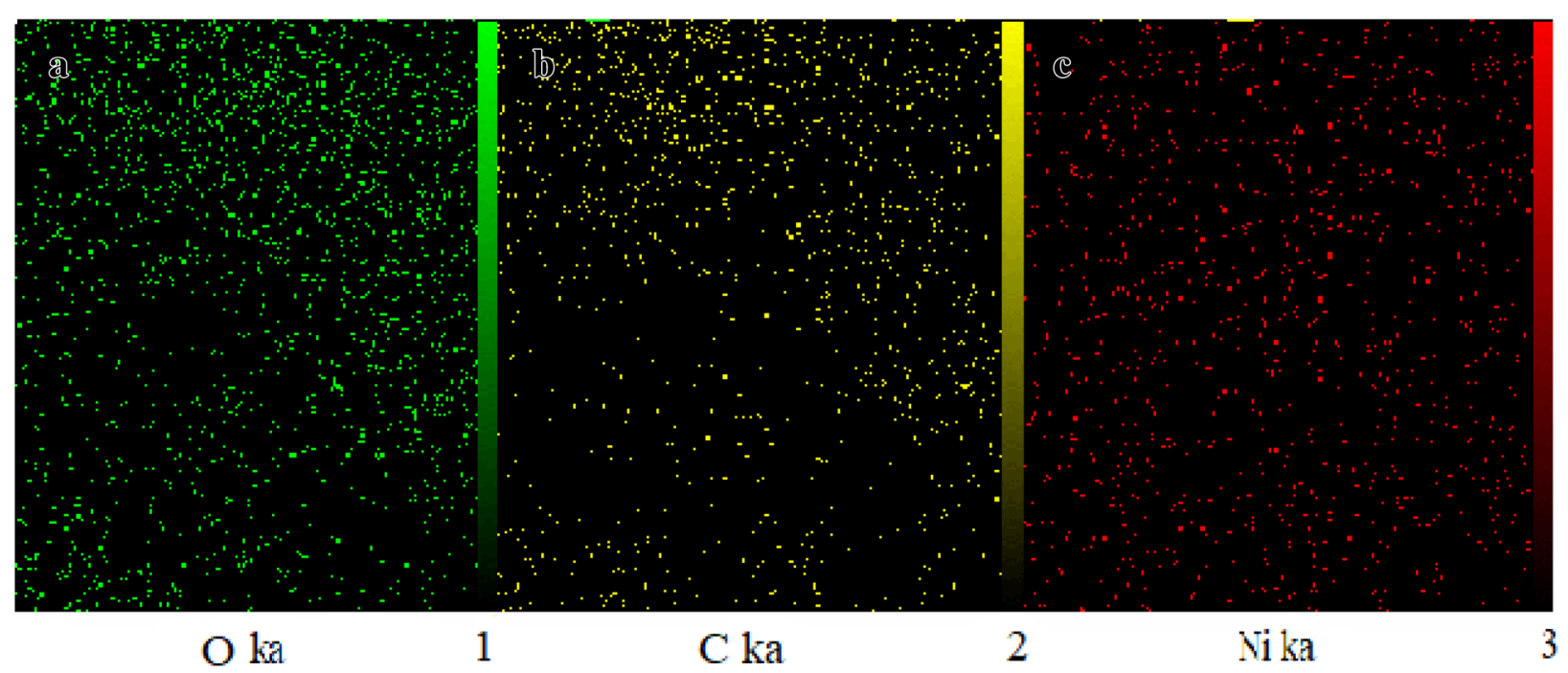

Figure 5. Elemental mapping of (a) oxygen, (b) carbon, and (c) nickel for Ni-CP.

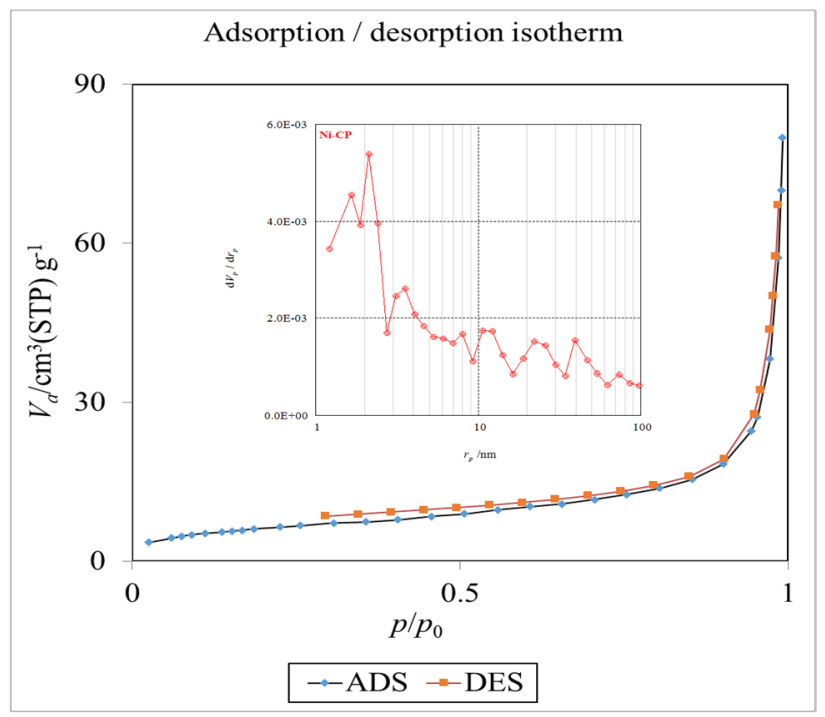

Figure 6. $\mathrm{N}_{2}$ adsorption-desorption isotherms of Ni-CP.

\begin{tabular}{|l|l|l|}
\hline $\mathrm{S}_{\mathrm{BET}}\left(\mathbf{m}^{\mathbf{2}} \mathbf{g}^{-1}\right)$ & Pore diameter $(\mathbf{n m})$ & Pore volume $\left(\mathrm{cm}^{\mathbf{3}} \mathbf{g}^{-1}\right)$ \\
\hline 22.65 & 19.34 & 0.11 \\
\hline
\end{tabular}

Table 1. Textural properties of Ni-CP.

In addition, the (111) Ni diffraction peak with appreciable intensity further confirms the presence of Ni metal in the prepared $\mathrm{Ni}-\mathrm{CP}^{45}$.

The mass ratios and the thermal stability of $\mathrm{Ni}-\mathrm{CP}$ were examined by the thermogravimetric analysis (TGA) (Fig. 8). In the TGA curve, the two obvious weight losses were found in the temperature range of $50-270{ }^{\circ} \mathrm{C}$, which can be attributed to the release of the physically adsorbed moisture (water) and DMF solvents from the sample ${ }^{15}$. In this sense, it was at above $270{ }^{\circ} \mathrm{C}$ that the framework degradation started. The main weight loss at $270-340^{\circ} \mathrm{C}$ was caused by the decomposition of citric acid ligand ${ }^{46}$. This result confirms the successful synthesis of Ni-CP and also indicates that the thermal stability of the sample is about $270{ }^{\circ} \mathrm{C}$. The DSC results also support the TGA data, based on weight loss of the sample, and approve the range of temperature stability of sample.

Catalytic study of Ni-CP. The catalytic activity of Ni-CP was investigated in the multicomponent reaction for the synthesis of polyhydroquinoline and 2,3-dihydroquinazolin-4(1H)-one derivatives. In the synthesis of 


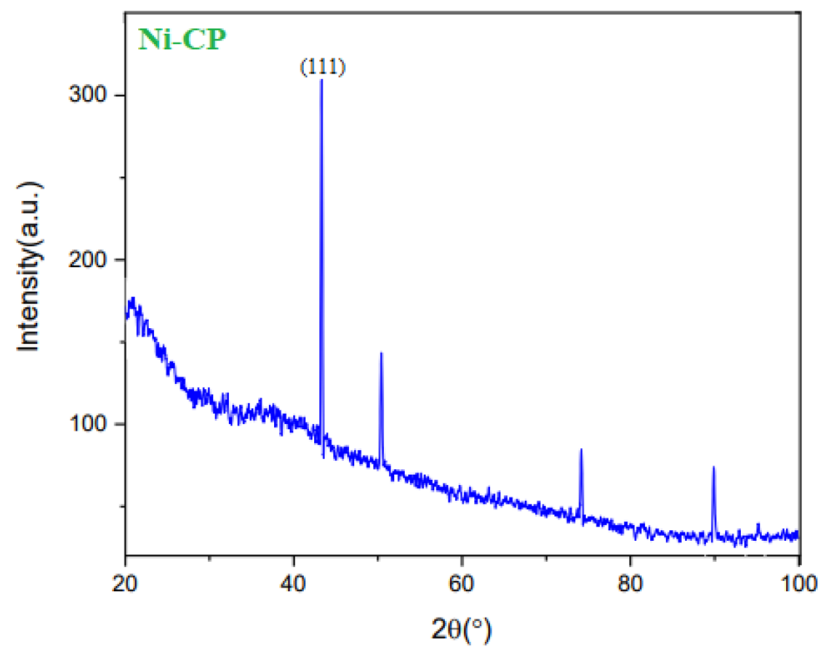

Figure 7. Normal XRD pattern of Ni-CP.

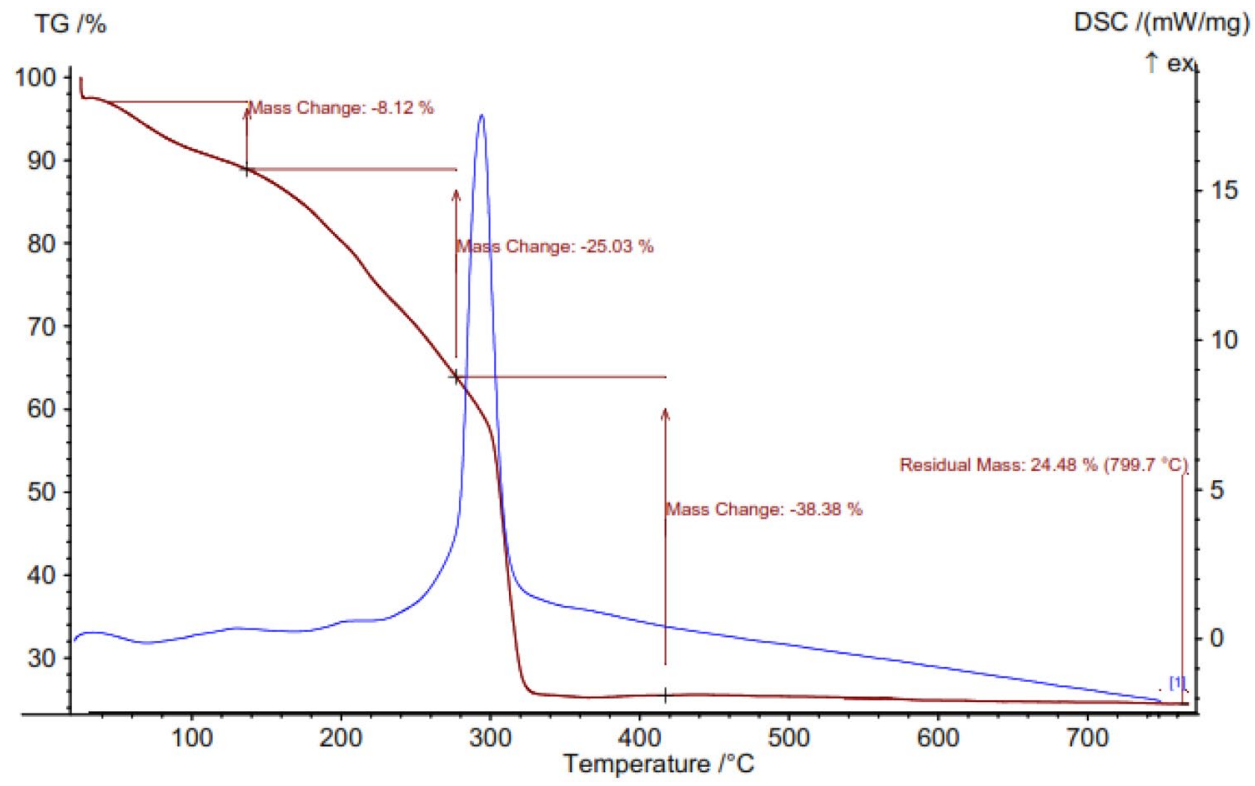

Figure 8. TGA diagram of Ni-CP.

polyhydroquinolines, 4-chlorobenzaldehyd was selected as a model substrate to obtain the best reaction conditions. The selected model reaction was tested in various conditions (Table 2). As shown, the model reaction did not proceed in the absence of Ni-CP (Table 2, entry 1). Meanwhile, the model reaction was completed in the presence of $5 \mathrm{mg}$ of this catalyst with a $97 \%$ yield (Table 2, entry 2). Also, the model reaction was performed in a wide range of solvents and temperature. As shown, the reaction is dependent on solvent and temperature in which ethanol at $80{ }^{\circ} \mathrm{C}$ shows the best results for the synthesis of polyhydroquinolines (Table 2).

To extend the application of $\mathrm{Ni}-\mathrm{CP}$ as a catalyst, the various aldehydes were investigated under obtained optimizing reaction conditions (Table 3). All products having electron-withdrawing groups or electron-donating groups were synthesized with good to excellent yields. In this investigation, electron-donating groups (such as $\mathrm{OH}, \mathrm{Me}, \mathrm{OMe}$ and $\mathrm{Nme}_{2}$ ) and electron-withdrawing groups (such as $\mathrm{Cl}, \mathrm{F}, \mathrm{Br}, \mathrm{CN}, \mathrm{NO}_{2}$ and $\mathrm{CF}_{3}$ ) on the aromatic ring of benzaldehydes were examined under obtained optimizing reaction conditions for the synthesis of the wide range of polyhydroquinoline derivatives.

In continuation, the catalytic activity of $\mathrm{Ni}$ - $\mathrm{CP}$ was examined for the synthesis of 2,3-dihydroquinazolin$4(1 H)$-one derivatives as an efficient, recyclable, stable, and commercially available CP catalyst. The synthesis of 2,3-dihydroquinazolin-4(1H)-ones via cyclocondensation of anthranilamide and aldehydes in the presence of $\mathrm{Ni}$-CP is shown in Table 4. In order to find the best reaction conditions, cyclocondensation of 4-chlorobenzaldehyde and anthranilamide was selected as model reaction (Table 4). At first, the effect of solvent was studied in 


\begin{tabular}{|l|l|l|l|l|l|}
\hline Entry & Catalyst $(\mathbf{m g})$ & Solvent & Temperature $\left({ }^{\circ} \mathbf{C}\right)$ & Time $(\mathbf{m i n})$ & Yield $^{\mathbf{a}}(\%)$ \\
\hline 1 & - & EtOH & Reflux & 90 & N.R \\
\hline 2 & 5 & EtOH & Reflux & 90 & 97 \\
\hline 3 & 5 & EtOH: $\mathrm{H}_{2} \mathrm{O}(1: 1)$ & 80 & 90 & 86 \\
\hline 4 & 5 & Solvent free & 80 & 90 & 90 \\
\hline 5 & 5 & PEG-400 & 80 & 30 & 78 \\
\hline 6 & 5 & DMSO & Reflux & 90 & 84 \\
\hline 7 & 2 & EtOH & Reflux & 90 & 67 \\
\hline 8 & 4 & EtOH & Reflux & 30 & 89 \\
\hline 9 & 6 & EtOH & Reflux & 30 & 97 \\
\hline 10 & 5 & EtOH & 25 & 30 & Trace \\
\hline 11 & 5 & EtOH & 50 & 30 & 48 \\
\hline 12 & 5 & EtOH & 65 & 68 \\
\hline 13 & 5 & EtOH & 70 & 84 \\
\hline
\end{tabular}

Table 2. Optimizing reaction conditions for the synthesis of polyhydroquinolines in the presence of Ni-CP. ${ }^{\mathrm{a}}$ Isolated yield. ${ }^{\mathrm{b}}$ No reaction.

the model reaction, in which the highest yields in lower reaction times were obtained in ethanol solvent (Table 4, entry 2). Meanwhile, other solvents such as PEG, $\mathrm{H}_{2} \mathrm{O}$, and DMF afforded low to moderate yields (Table 4, entries 3-5). Then, the amount of Ni-CP and the effect of temperature were also examined. As shown in Table 4, this reaction requires $6 \mathrm{mg}$ of $\mathrm{Ni}-\mathrm{CP}$ as a catalyst in the best conditions. Also, the best results were obtained at $80^{\circ} \mathrm{C}$. Meanwhile, lower yields were observed at $25^{\circ} \mathrm{C}, 50^{\circ} \mathrm{C}$ and $70{ }^{\circ} \mathrm{C}$ (Table 4, entries 10-12).

bo reaction.

After optimization of the reaction conditions, we have investigated the synthesis of a series of 2,3-dihydroquinazolin- $4(1 \mathrm{H})$-ones to explore the scope of this procedure (Table 5). In these studies, various functional groups on the aromatic ring of an aldehyde such as $\mathrm{OH}, \mathrm{Me}, \mathrm{OMe}, \mathrm{Cl}, \mathrm{Br}, \mathrm{F}$ and $\mathrm{NO}_{2}$ were well tolerated. Therefore, this procedure is efficient for the synthesis of a wide range of 2,3-dihydroquinazolin-4(1H)-ones including electron-donating and electron- withdrawing substituents.

Based on the previous reports, the possible mechanism for the synthesis of 2,3-dihydroquinazolin-4(1H)one derivatives in the presence of Lewis acid can be suggested in (Fig. 9) ${ }^{28}$. This mechanism has several steps in which the first step involves activation of aldehyde by Ni-CP catalyst. The second step includes attacking active aldehyde by the amine group of 2-amino benzamide which followed by the dehydration reaction led to the synthesis of imine I. Intermediate I is converted to intermediate II by an intermolecular reaction. This step is included tautomerization of the amide and an intramolecular nuclear attack on carbon of imine. Finally, 2,3-dihydroquinazolin-4(1H)-one derivatives were synthesized by the protons transfer and Ni-CP catalyst was regenerated for new cycle ${ }^{28}$.

Recycling ability and leaching study of the catalyst. Recyclability is one of the most important properties of heterogeneous catalysts. The recyclability of the Ni-CP catalyst was analyzed in a typical [2+3] cycloaddition of anthranilamide and 4-chloro-benzaldehyde under the optimized reaction conditions. Figure 10 shows that $\mathrm{Ni}-\mathrm{CP}$ catalyst can be reused up to 5 times without any significant loss of its activity.

The structure of reused catalyst was considered using FT-IR and XRD analysis. The FT-IR (Fig. 11) and XRD (Fig. 12) did not show any significant change compared to the fresh catalyst. All of the peaks of fresh catalyst are existed in the recovered catalyst.

In order to indicate the heterogeneous nature of $\mathrm{Ni}-\mathrm{CP}$, nickel leaching of this catalyst was studied. In this regard, the synthesis of 2,3-dihydroquinazolin-4(1H)-one using condensation of 4-chlorobenzaldehyde with 2 -amino benzamide was selected as a model reaction. After completion of the reaction, the catalyst was removed by simple filtration and the amount of nickel was calculated in filtered solution by AAS which was found to be $0.0000370 \mathrm{mmol} \mathrm{mL}^{-1}$. As known, this very small amount of nickel doesn't have a significant effect on the reaction progress. Therefore, the completion of the reaction could be dependent on the heterogeneous nickel species. It was also proved by the hot filtration test that the $\mathrm{Ni}-\mathrm{CP}$ played a catalytic role in the reaction without the $\mathrm{Ni}$ leaching into the solution. 
www.nature.com/scientificreports/

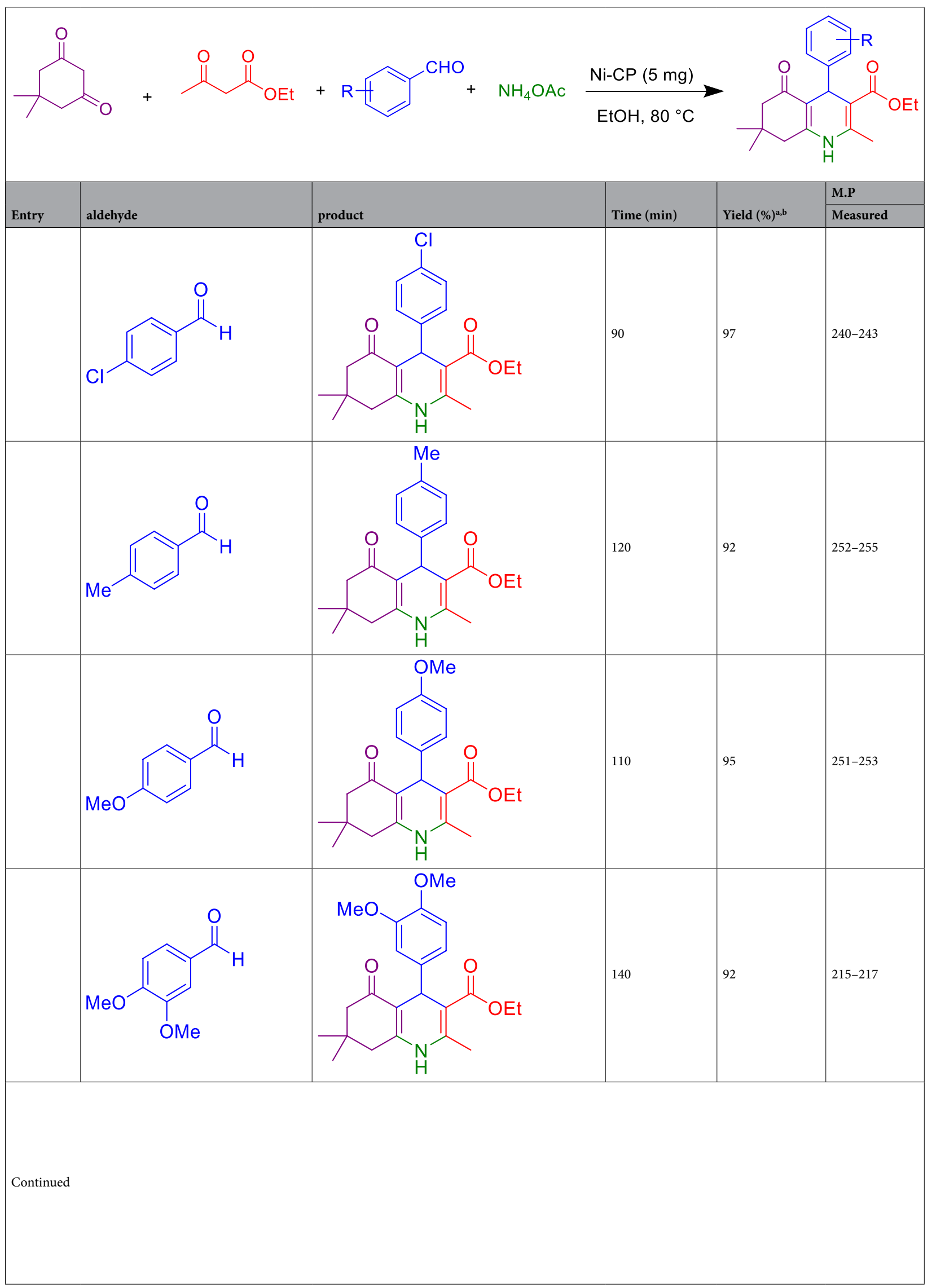

Scientific Reports |

(2021) 11:24475 |

https://doi.org/10.1038/s41598-021-03857-w

natureportfolio

8 
www.nature.com/scientificreports/

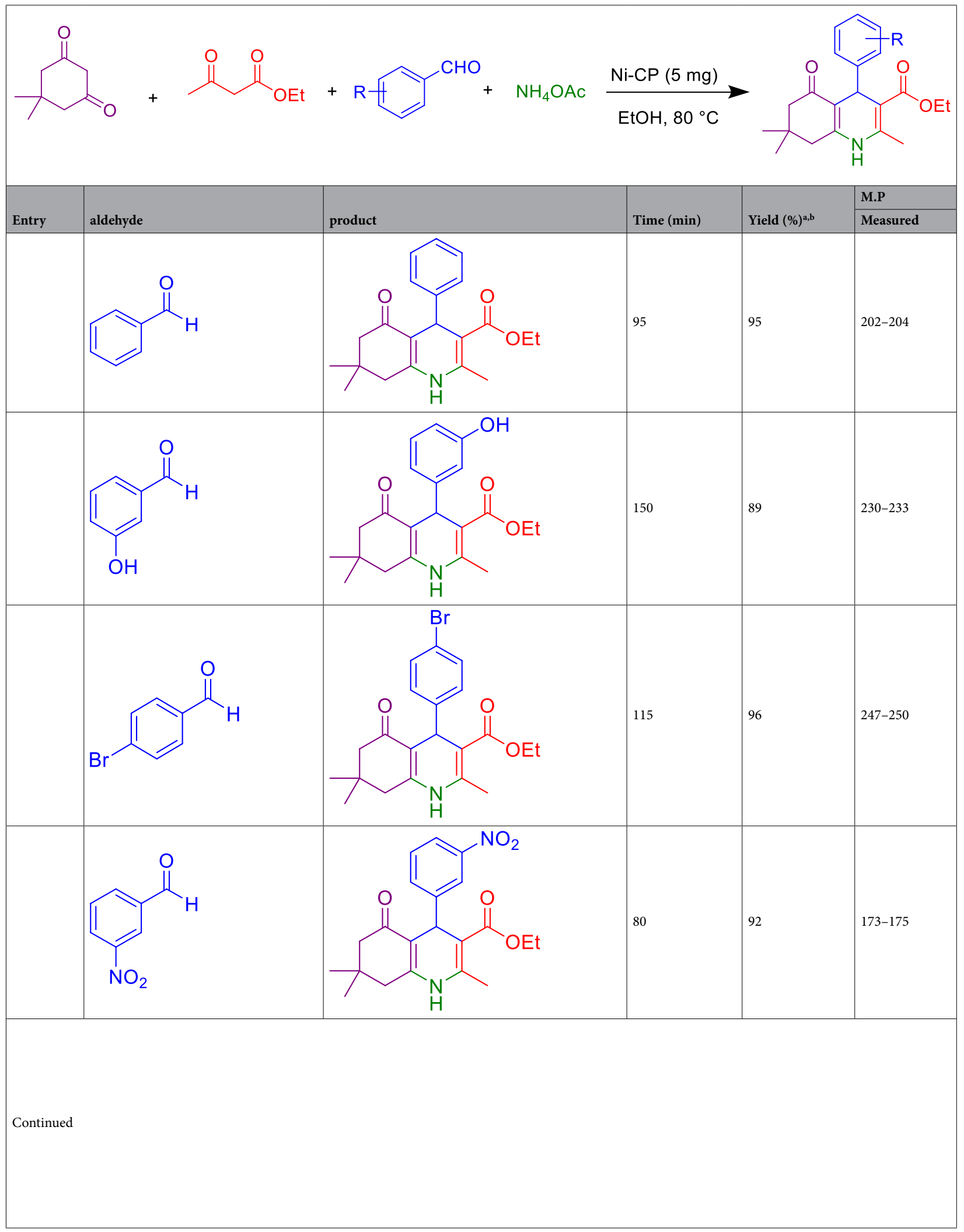

Scientific Reports |

(2021) 11:24475 |

https://doi.org/10.1038/s41598-021-03857-w

natureportfolio

9 


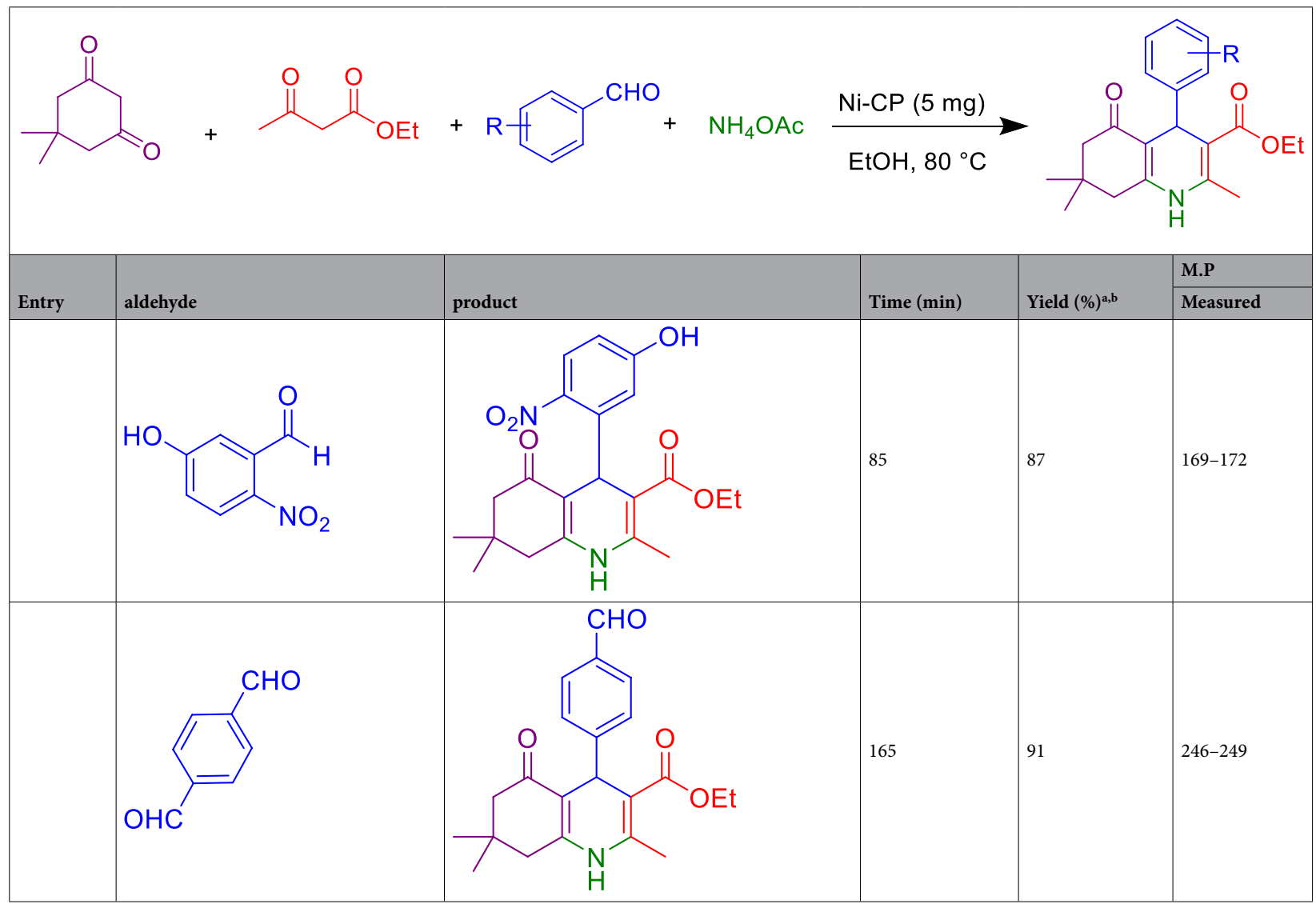

Table 3. Synthesis of polyhydroquinoline derivatives catalysed by Ni-CP. ${ }^{a}$ Isolated yield. ${ }^{b}$ Reaction conditions: Aromatic aldehyde (1 $\mathrm{mmol})$, dimedone $(1 \mathrm{mmol})$, ethyl acetoacetate $(1 \mathrm{mmol})$, ammonium acetate (1.2 mmol), Ni-CP (5 mg) in ethanol under reflux conditions.

\begin{tabular}{|c|c|c|c|c|c|}
\hline Entry & Catalyst (mg) & Solvent & Temperature $\left({ }^{\circ} \mathrm{C}\right)$ & Time (min) & Yield (\%) ${ }^{\mathrm{a}}$ \\
\hline 1 & - & EtOH & Reflux & 120 & N.R ${ }^{b}$ \\
\hline 2 & 6 & $\mathrm{EtOH}$ & Reflux & 45 & 96 \\
\hline 3 & 6 & DMF & Reflux & 45 & Trace \\
\hline 4 & 6 & PEG-400 & Reflux & 45 & 89 \\
\hline 5 & 6 & $\mathrm{H}_{2} \mathrm{O}$ & Reflux & 45 & 66 \\
\hline 6 & 1 & $\mathrm{EtOH}$ & Reflux & 45 & Trace \\
\hline 7 & 3 & $\mathrm{EtOH}$ & Reflux & 45 & 58 \\
\hline 8 & 5 & $\mathrm{EtOH}$ & Reflux & 45 & 88 \\
\hline 9 & 8 & $\mathrm{EtOH}$ & Reflux & 45 & 96 \\
\hline 10 & 6 & $\mathrm{EtOH}$ & 25 & 45 & Trace \\
\hline 11 & 6 & $\mathrm{EtOH}$ & 50 & 45 & 51 \\
\hline 12 & 6 & EtOH & 70 & 45 & 87 \\
\hline
\end{tabular}

Table 4. Optimizing reaction conditions for the synthesis of 2,3-dihydroquinazolin-4(1H)-ones in the

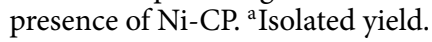




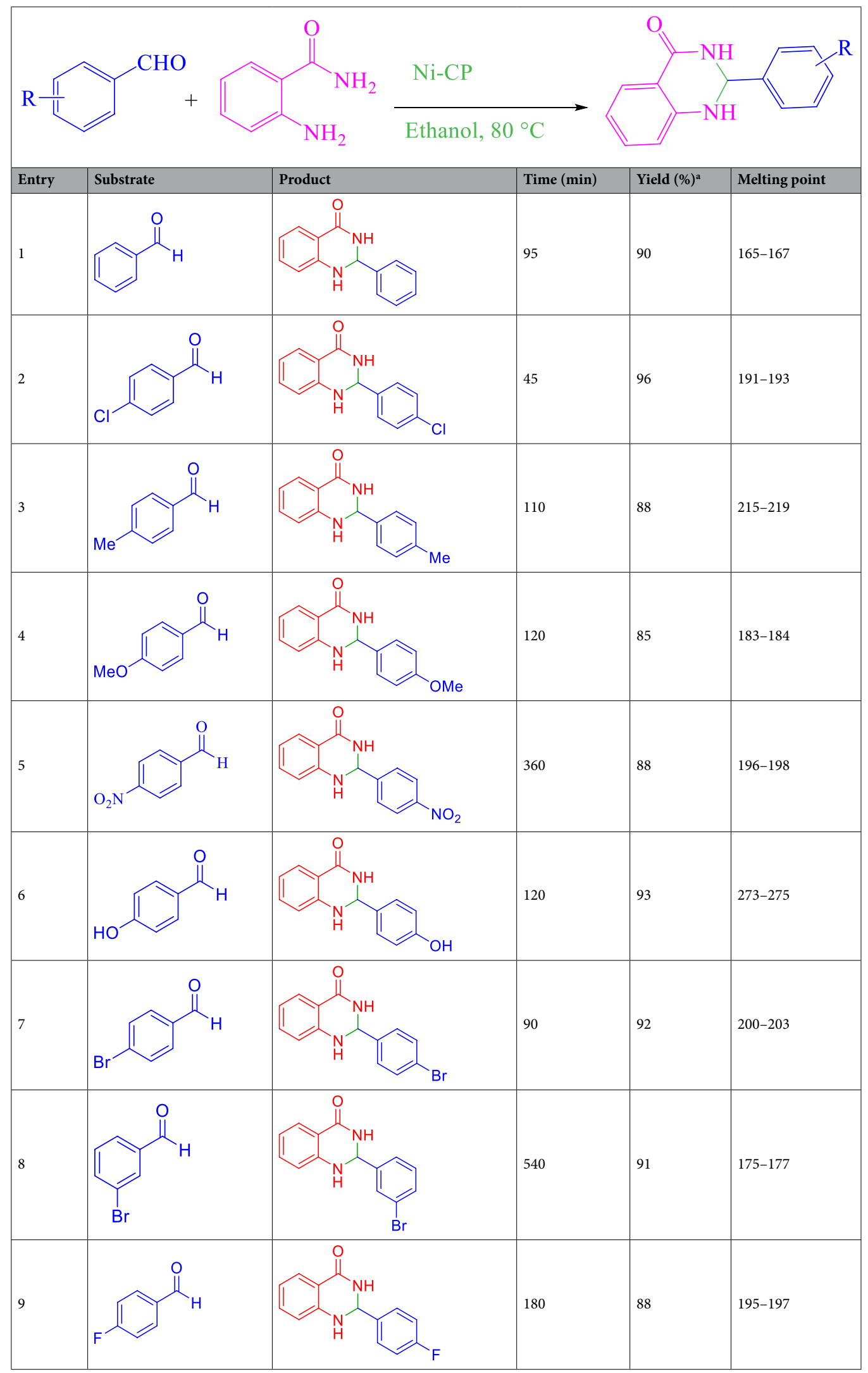

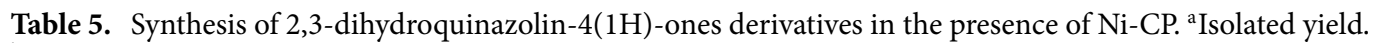
${ }^{\mathrm{b}}$ Reaction conditions: 4-Chlorobenzaldehyde ( $\left.1 \mathrm{mmol}\right)$, Anthranilamide (2-aminobenzamide) ( $\left.1 \mathrm{mmol}\right)$, $\mathrm{Ni}-\mathrm{CP}(6 \mathrm{mg})$ in ethanol under reflux conditions. 


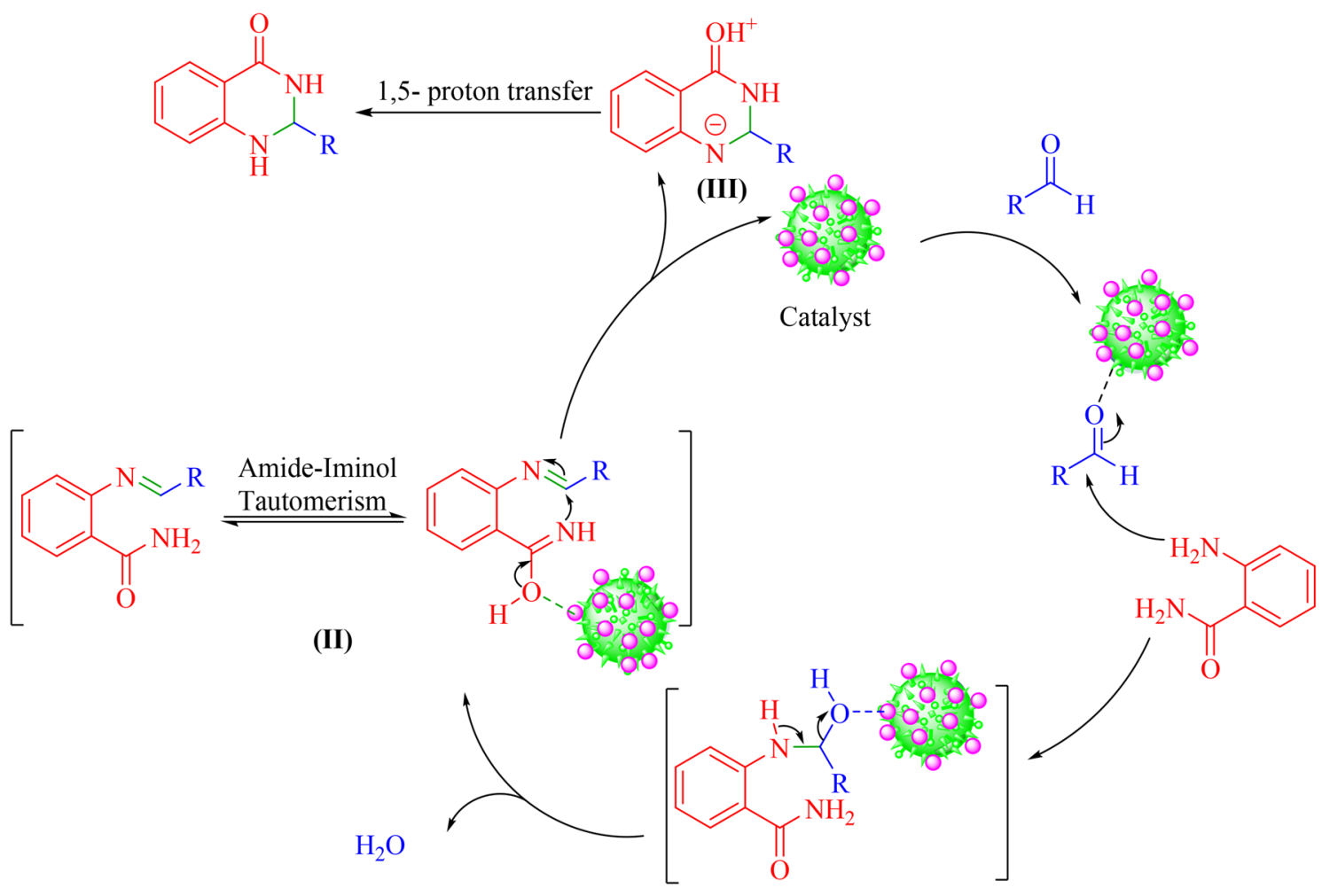

(I)

Figure 9. Proposed mechanism for the synthesis of 2,3-dihydroquinazolin-4(1H)-ones catalyzed by Ni-CP.

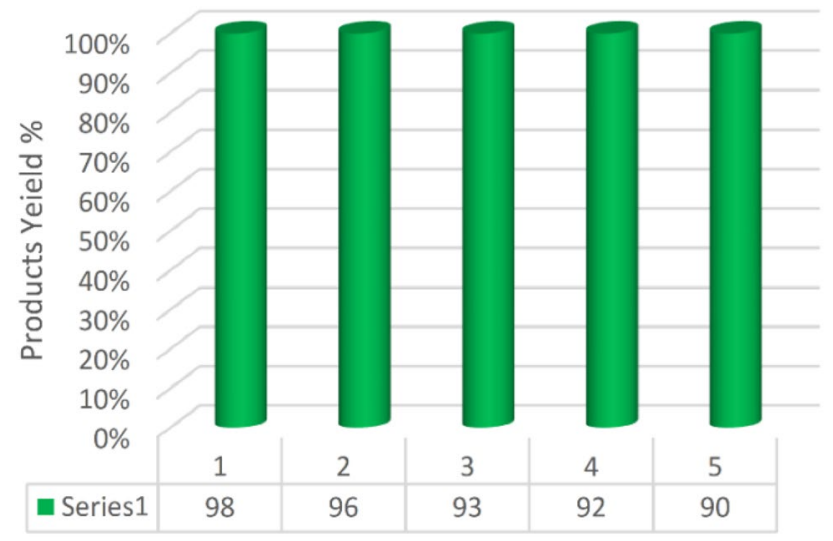

Figure 10. Recyclability of Ni-CP catalyst.

Comparison of the catalyst. The efficiency of Ni-CP was investigated by comparison of our results on the synthesis of Polyhydroquinolines and 2,3-dihydroquinazolin-4(1H)-ones model reactions with the previous methods (Table 6). The products were obtained in higher yields over faster times in the presence of Ni-CP. Also, this catalyst has several advantages in terms of non-toxicity, price, stability and easy separation.

\section{Conclusion}

In this work, nickel nitrate and citric acid nitrate were used to synthesis a new CP catalyst (Ni-CP). This CP catalyst was characterized by AAS, WDX, EDS, SEM, TGA, XRD and $\mathrm{N}_{2}$ adsorption-desorption analysis. Ni-CP was successfully described as an efficient and recyclable catalyst in the synthesis of polyhydroquinoline and 2,3-dihydroquinazolin-4(1H)-one derivatives in which all products were prepared in good yields. This catalyst has several advantages such as non-toxicity, price, stability and easy separation. 


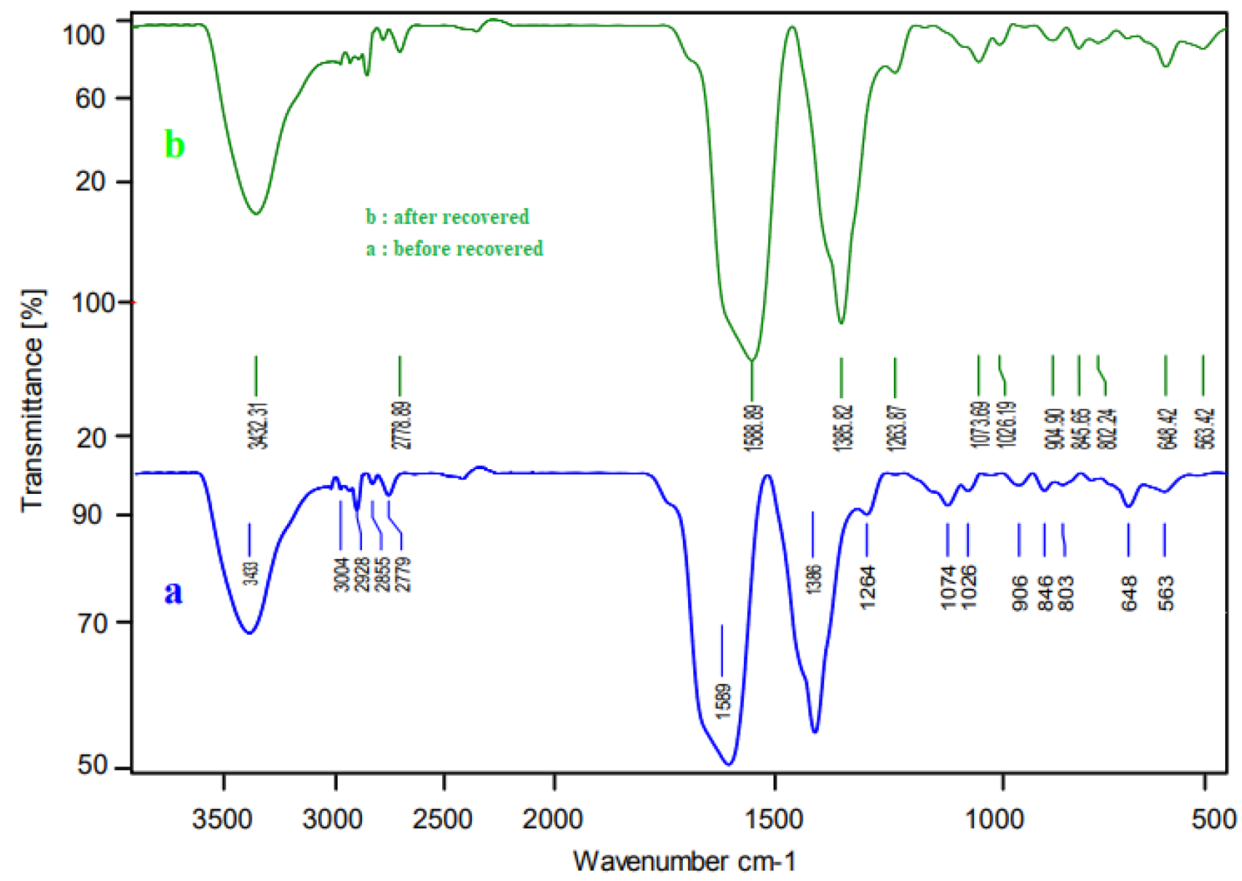

Figure 11. FT-IR analysis of Ni-CP catalyst.

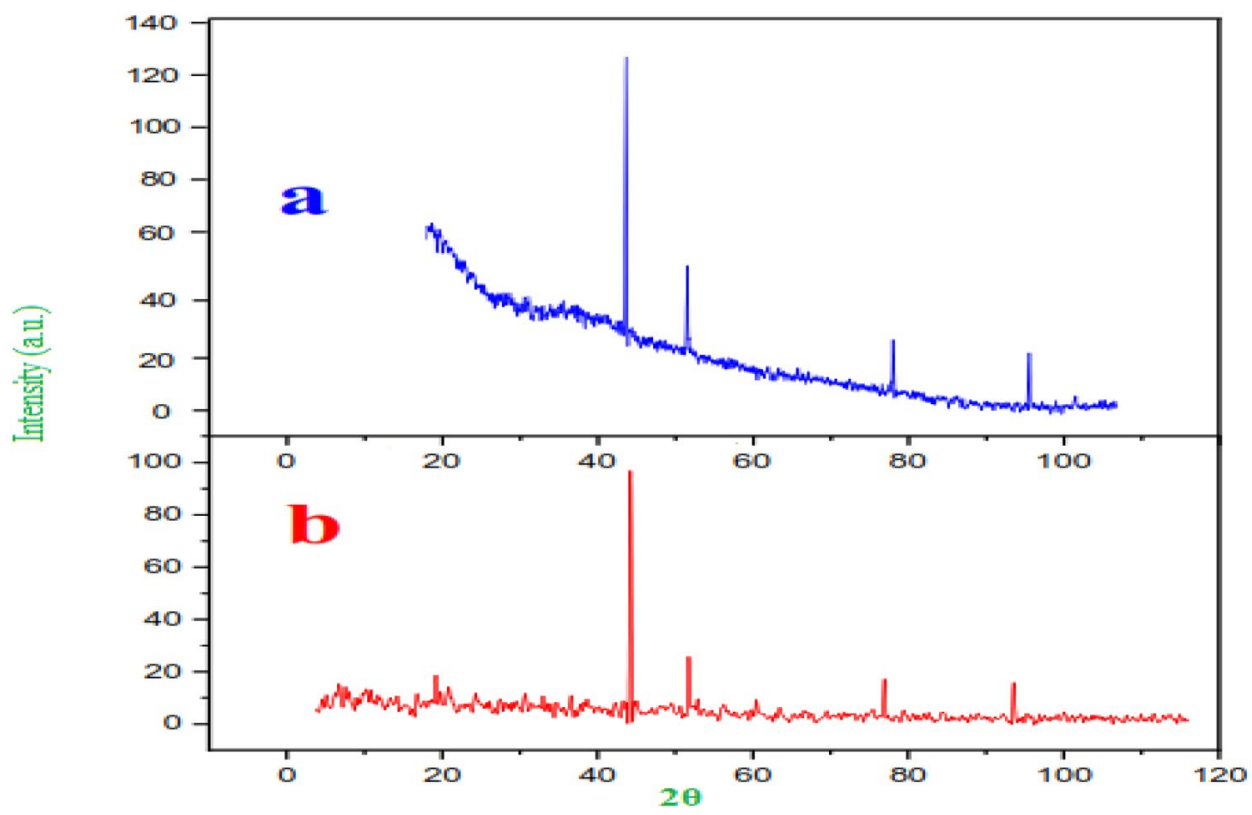

Figure 12. $\mathrm{P}-\mathrm{XRD}$ analysis of Ni-CP catalyst. 


\begin{tabular}{|c|c|c|c|c|c|}
\hline Entry & Reaction & Catalyst & Time (min) & Yield $(\%)^{a}$ & Ref. \\
\hline 1 & Polyhydroquinoline & $\mathrm{FeAl}_{2} \mathrm{O}_{4}$ & 180 & 90 & 26 \\
\hline 2 & Polyhydroquinoline & $\mathrm{CoFe}_{2} \mathrm{O}_{4} @ \mathrm{Pr}$ & 145 & 96 & 47 \\
\hline 3 & Polyhydroquinoline & $\mathrm{Fe}_{3} \mathrm{O}_{4} @ \mathrm{D}-\mathrm{NH}-\left(\mathrm{CH}_{2}\right)_{4}-\mathrm{SO}_{3} \mathrm{H}$ & 90 & 86 & 48 \\
\hline 4 & Polyhydroquinoline & AIL-SCMNPs & 15 & 80 & 49 \\
\hline 5 & Polyhydroquinoline & $\mathrm{Fe}_{3} \mathrm{O}_{4} @ \mathrm{GA} @ \mathrm{IG}$ & 45 & 89 & 50 \\
\hline 6 & Polyhydroquinoline & Nickel nitrate & 90 & 52 & This work \\
\hline 7 & Polyhydroquinoline & $\mathrm{Ni}-\mathrm{CP}$ & 90 & 97 & This work \\
\hline 8 & 2,3-Dihydroquinazolin-4 (1H)-one & a-D-glucose & 180 & 61 & 51 \\
\hline 9 & 2,3-Dihydroquinazolin-4 (1H)-one & SBA-16/GPTMS-TSC-Cu ${ }^{\mathrm{I}}$ & 35 & 95 & 52 \\
\hline 10 & 2,3-Dihydroquinazolin-4 (1H)-one & $\mathrm{CoFe}_{2} \mathrm{O}_{4} @ \mathrm{Pr}$ & 60 & 97 & 28 \\
\hline 11 & 2,3-Dihydroquinazolin-4 (1H)-one & Amberlyst-15 & 60 & 85 & 53 \\
\hline 12 & 2,3-Dihydroquinazolin-4 (1H)-one & Nickel nitrate & 45 & 63 & This work \\
\hline 13 & 2,3-Dihydroquinazolin-4 (1H)-one & $\mathrm{Ni}-\mathrm{CP}$ & 45 & 96 & This work \\
\hline
\end{tabular}

Table 6. Comparison results of Ni-CP with other catalysts in the synthesis of Polyhydroquinolines and 2,3-dihydroquinazolin-4(1H)-one.

Received: 16 August 2021; Accepted: 9 December 2021

Published online: 28 December 2021

\section{References}

1. Gore, R. P. \& Rajput, A. P. A review on recent progress in multicomponent reactions of pyrimidine synthesis. Drug Invent. Today 5, 148-152 (2013).

2. Ghorbani-Choghamarani, A. et al. Nano aluminium nitride as a solid source of ammonia for the preparation of hantzsch 1,4-dihydropyridines and bis-(1,4-dihydropyridines) in water via one pot multicomponent reaction. J. Braz. Chem. Soc. 22, 525-531 (2011).

3. Kazemi, M. \& Mohammadi, M. Magnetically recoverable catalysts: Catalysis in synthesis of polyhydroquinolines. Appl. Organomet. Chem. 34, e5400 (2020).

4. Climent, M. J., Corma, A. \& Iborra, S. Homogeneous and heterogeneous catalysts for multicomponent reactions. RSC Adv. 2, 16-58 (2012).

5. Jiang, B., Rajale, T., Wever, W., Tu, S. J. \& Li, G. Multicomponent reactions for the synthesis of heterocycles. Chem. Asian J. 5, 2318-2335 (2010).

6. Neochoritis, C. G., Zhao, T. \& Dömling, A. Tetrazoles via multicomponent reactions. Chem. Rev. 119, 1970-2042 (2019).

7. Estévez, V., Villacampa, M. \& Menéndez, J. C. Multicomponent reactions for the synthesis of pyrroles. Chem. Soc. Rev. 39, 4402 (2010).

8. Saranya, S., Aneeja, T., Neetha, M. \& Anilkumar, G. Recent advances in the iron-catalysed multicomponent reactions. Appl. Organomet. Chem. 34, 1-10 (2020).

9. Das, S. Recent applications of ninhydrin in multicomponent reactions. RSC Adv. 10, 18875-18906 (2020).

10. Vavsari, V. F., Shakeri, P. \& Balalaie, S. Application of chiral isocyanides in multicomponent reactions. Curr. Org. Chem. 24, 178-199 (2020).

11. Atashkar, B., Rostami, A., Gholami, H. \& Tahmasbi, B. Magnetic nanoparticles Fe3O4-supported guanidine as an efficient nanocatalyst for the synthesis of $2 \mathrm{H}$-indazolo[2,1-b]phthalazine-triones under solvent-free conditions. Res. Chem. Intermed. 41, 3675-3681 (2015).

12. Mohammadi, M., Khodamorady, M., Tahmasbi, B., Bahrami, K. \& Ghorbani-Choghamarani, A. Boehmite nanoparticles as versatile support for organic-inorganic hybrid materials: Synthesis, functionalization, and applications in eco-friendly catalysis. J. Ind. Eng. Chem. https://doi.org/10.1016/j.jiec.2021.02.001 (2021).

13. Shen, C. \& Wu, X. F. Palladium-catalyzed carbonylative multicomponent reactions. Chem. Eur. J. 23, 2973-2987 (2017).

14. Nikoorazm, M., Mohammadi, M. \& Khanmoradi, M. Zirconium@guanine@MCM-41 nanoparticles: An efficient heterogeneous mesoporous nanocatalyst for one-pot, multi-component tandem Knoevenagel condensation-Michael addition-cyclization reactions. Appl. Organomet. Chem. 34, e5704 (2020).

15. Hussain-Khil, N., Ghorbani-Choghamarani, A. \& Mohammadi, M. A new silver coordination polymer based on 4,6-diamino2-pyrimidinethiol: synthesis, characterization and catalytic application in asymmetric Hantzsch synthesis of polyhydroquinolines. Sci. Rep. 11, 15657 (2021).

16. Valente, A., Mortreux, A., Visseaux, M. \& Zinck, P. Coordinative chain transfer polymerization. Chem. Rev. 113, 3836-3857 (2013).

17. Siddiqui, K. A., Bharati, A. K. \& Lama, P. Coordination polymers based on $\mu 2 \eta 1: \eta 1$ and $\mu 2 \eta 2: \eta 2$ bridging mode of pyridyl carboxylate: Ionic liquid-induced hydrothermal synthesis, structural and thermogravimetric analysis. J. Iran. Chem. Soc. 15, 2315-2324 (2018).

18. Sun, Y. et al. Metal-organic framework nanocarriers for drug delivery in biomedical applications. Nano-Micro Lett. 12, 10 (2020).

19. Lorignon, F., Gossard, A. \& Carboni, M. Hierarchically porous monolithic MOFs: An ongoing challenge for industrial-scale effluent treatment. Chem. Eng. J. 393, 123 (2020).

20. Jiang, Q., Desbois, N., Wang, S. \& Gros, C. P. Recent developments in dipyrrin based metal complexes: Self-assembled nanoarchitectures and materials applications. J. Porphyr. Phthalocyanines 24, 646-661 (2020).

21. García-Valdivia, A. A. et al. 2D-Coordination polymers based on 1: H-indazole-4-carboxylic acid and transition metal ions: Magnetic, luminescence and biological properties. CrystEngComm 22, 5086-5095 (2020).

22. Hashemzadeh, A., Amini, M. M., Najafi, E. \& Khavasi, H. R. Effects of length and number of aromatic rings in carboxylic acid ligands on structure and optical properties of lead(II) coordination polymers. Res. Chem. Intermed. 43, 5741-5753 (2017).

23. Nikoorazm, M. \& Erfani, Z. Fe3O4@MCM-41@Zn-Arg: As a novel, magnetically recoverable and ecofriendly nanocatalyst for the synthesis of disulfides, sulfoxides and 2,3-dihydroquinazolin-4(1H)-ones. Inorg. Nano-Metal Chem. https://doi.org/10.1080/ 24701556.2020.1802750 (2020). 
24. Ghafouri-Nejad, R. \& Hajjami, M. Synthesis and characterization of $\mathrm{Cu}-\mathrm{N}, \mathrm{N}^{\prime}$-Dicyclohexylcarbodiimide supported on CMK-3 as a novel, efficient and recoverable nanocatalyst for synthesis of tetrazole, polyhydroquinoline, and sulfoxide derivatives. React. Kinet. Mech. Catal. 129, 371-389 (2020).

25. Ghorbani-Choghamarani, A., Mohammadi, M., Tamoradi, T. \& Ghadermazi, M. Covalent immobilization of Co complex on the surface of SBA-15: Green, novel and efficient catalyst for the oxidation of sulfides and synthesis of polyhydroquinoline derivatives in green condition. Polyhedron 158, 25-35 (2019).

26. Ghorbani-Choghamarani, A., Mohammadi, M., Shiri, L. \& Taherinia, Z. Synthesis and characterization of spinel FeAl2O4 (hercynite) magnetic nanoparticles and their application in multicomponent reactions. Res. Chem. Intermed. 45, 5705-5723 (2019).

27. Ghorbani-Choghamarani, A., Aghavandi, H. \& Mohammadi, M. Mesoporous SBA-15@n-Pr-THAM-ZrO organic-inorganic hybrid: as a highly efficient reusable nanocatalyst for the synthesis of polyhydroquinolines and 2,3-dihydroquinazolin-4 (1h)ones. J. Porous Mater. https://doi.org/10.1007/s10934-021-01063-7 (2021).

28. Tamoradi, T., Mousavi, S. M. \& Mohammadi, M. Praseodymium(iii) anchored on CoFe2O4 MNPs: an efficient heterogeneous magnetic nanocatalyst for one-pot, multi-component domino synthesis of polyhydroquinoline and 2,3-dihydroquinazolin- $4(1 \mathrm{H})$ one derivatives. New J. Chem. 44, 3012-3020 (2020).

29. Karad, S. C. et al. Green synthesis and pharmacological screening of polyhydroquinoline derivatives bearing a fluorinated 5-aryloxypyrazole nucleus. RSC Adv. 5, 16000-16009 (2015).

30. SheikMansoor, S., Aswin, K., Logaiya, K. \& Sudhan, S. P. N. An efficient one-pot multi component synthesis of polyhydroquinoline derivatives through Hantzsch reaction catalysed by Gadolinium triflate. Arab. J. Chem. 10, S546-S553 (2017).

31. Wang, Z. et al. Design, synthesis and antiviral activity of novel quinazolinones. Eur. J. Med. Chem. 53, 275-282 (2012).

32. Gali, R. et al. Indolylmethylene benzo[h]thiazolo[2,3-b]quinazolinones: Synthesis, characterization and evaluation of anticancer and antimicrobial activities. Bioorg. Med. Chem. Lett. 24, 4239-4242 (2014).

33. Badolato, M., Aiello, F. \& Neamati, N. 2,3-Dihydroquinazolin-4(1 H )-one as a privileged scaffold in drug design. RSC Adv. 8, 20894-20921 (2018)

34. Rupnar, B. D., Kachave, T. R., Jawale, P. D., Shisodia, S. U. \& Pawar, R. P. Green and efficient synthesis of 2, 3-dihydroquinazolin4(1H)-ones in aqueous medium using $\mathrm{ZnFe} 2 \mathrm{O} 4$ catalyst under microwave irradiation. J. Iran. Chem. Soc. 14, 1853-1858 (2017).

35. Azizi, N. \& Edrisi, M. Practical approach to 2-thioxo-2,3-dihydroquinazolin-4(1 H )-one via dithiocarbamate-anthranilic acid reaction. Chinese Chem. Lett. 28, 109-112 (2017).

36. Zhang, X.-B., Cheng, G., Zhang, W.-J., Shen, G.-L. \& Yu, R.-Q. A fluorescent chemical sensor for Fe3+ based on blocking of intramolecular proton transfer of a quinazolinone derivative. Talanta 71, 171-177 (2007).

37. Anthony, S. P. Polymorph-dependent solid-state fluorescence and selective metal-ion-sensor properties of 2-(2-hydroxyphenyl)4(3H)-quinazolinone. Chem. Asian J. 7, 374-379 (2012).

38. Zhang, W. J., Peng, J., Lu, L. M., Zhang, J. \& Zhang, X. B. 2-(2'-Hydroxyphenyl)-4(3H)-quinazolinone derivatives based fluorescent probes for mercury(II) via an intramolecular proton transfer mechanism. Int. J. Environ. Anal. Chem. 92, 810-820 (2012).

39. Aw, J. et al. Synthesis and characterization of 2-(2'-hydroxy-5'-chlorophenyl)-6-chloro-4 (3 H)-quinazolinone-based fluorogenic probes for cellular imaging of monoamine oxidases. Chem. Asian J. 5, 1317-1321 (2010).

40. Zhang, C. et al. Facile synthesis of a two-dimensional layered Ni-MOF electrode material for high performance supercapacitors. RSC Adv. 8, 17747-17753 (2018).

41. Koolivand, M., Nikoorazm, M., Ghorbani-Choghamarani, A. \& Tahmasbi, B. Cu-citric acid metal-organic framework: Synthesis, characterization and catalytic application in Suzuki-Miyaura cross-coupling reaction and oxidation of sulfides. Appl. Organomet. Chem. 1, e6434 (2021).

42. Alothman, Z. A review: Fundamental aspects of silicate mesoporous materials. Materials 5, 2874-2902 (2012).

43. NowsathRifaya, M., Theivasanthi, T. \& Alagar, M. Chemical capping synthesis of nickel oxide nanoparticles and their characterizations studies. Nanosci. Nanotechnol. 2, 134-138 (2012).

44. Theivasanthi, T. \& Alagar, M. An insight analysis of nano sized powder of jackfruit seed. Nano Biomed. Eng. 3, 163-168 (2011).

45. Ghorbani-Choghamarani, A., Taherinia, Z. \& Mohammadi, M. Facile synthesis of Fe3O4@GlcA@Ni-MOF composites as environmentally green catalyst in organic reactions. Environ. Technol. Innov. https://doi.org/10.1016/j.eti.2021.102050 (2021).

46. Wyrzykowski, D., Hebanowska, E., Nowak-Wiczk, G., Makowski, M. \& Chmurzyński, L. Thermal behaviour of citric acid and isomeric aconitic acids. J. Therm. Anal. Calorim. 104, 731-735 (2011).

47. Tamoradi, T., Ghadermazi, M. \& Ghorbani-Choghamarani, A. Ni(II)-Adenine complex coated Fe3O4 nanoparticles as high reusable nanocatalyst for the synthesis of polyhydroquinoline derivatives and oxidation reactions. Appl. Organomet. Chem. 32, e3974 (2018).

48. Alinezhad, H., Tarahomi, M., Maleki, B. \& Amiri, A. SO 3 H-functionalized nano-MGO-D-NH 2: Synthesis, characterization and application for one-pot synthesis of pyrano[2,3-d]pyrimidinone and tetrahydrobenzo[b]pyran derivatives in aqueous media. Appl. Organomet. Chem. 33, 123 (2019).

49. Taheri, N., Heidarizadeh, F. \& Kiasat, A. A new magnetically recoverable catalyst promoting the synthesis of 1,4-dihydropyridine and polyhydroquinoline derivatives via the Hantzsch condensation under solvent-free conditions. J. Magn. Magn. Mater. 428, 481-487 (2017).

50. Pourian, E., Javanshir, S., Dolatkhah, Z., Molaei, S. \& Maleki, A. Ultrasonic-assisted preparation, characterization, and use of novel biocompatible core/shell Fe3O4@GA@Isinglass in the synthesis of 1,4-dihydropyridine and 4 H-pyran derivatives. ACS Omega 3, 5012-5020 (2018).

51. dos Santos, T. et al. Glucose as an eco-friendly reductant in a one-pot synthesis of 2,3-dihydroquinazolin-4(1H)-ones. European J. Org. Chem. 2020, 6429-6432 (2020).

52. Erfan, M. A., Akhlaghinia, B. \& Ghodsinia, S. S. E. An efficient green protocol for synthesis of 2,3-dihydroquinazolin-4(1 h )-ones using SBA-16/GPTMS-TSC-Cu I under solvent-free conditions. Chem. Select 5, 2306-2316 (2020).

53. Bharate, S. B. et al. Efficient synthesis of 2,3-dihydroquinazolin-4(1H)-ones using heterogeneous solid acid catalysts: Unexpected formation of 2,3-dihydro-2-(4-(tetrahydro-2H-pyran-2-yloxy)butyl)-quinazolin-4(1H)-one. ARKIVOC 2012, 308-318 (2012).

\section{Acknowledgements}

The authors would like to thank the research facilities of Ilam University and Bu-Ali Sina University for financial support of this research project.

\section{Author contributions}

M.K. did the experimental works, methodology, software and Writing-draft, review \& editing. M.N. supervised the research project, Writing-review \& editing and is the primary corresponding author of the manuscript. A.G.-C. supervised the research project and is the secondary corresponding author of the manuscript. R.A. did the investigation and data curation. B.T. wrote the manuscript draft. 


\section{Competing interests}

The authors declare no competing interests.

\section{Additional information}

Supplementary Information The online version contains supplementary material available at https://doi.org/ 10.1038/s41598-021-03857-w.

Correspondence and requests for materials should be addressed to M.N. or A.G.-C.

Reprints and permissions information is available at www.nature.com/reprints.

Publisher's note Springer Nature remains neutral with regard to jurisdictional claims in published maps and institutional affiliations.

(c) (1) Open Access This article is licensed under a Creative Commons Attribution 4.0 International License, which permits use, sharing, adaptation, distribution and reproduction in any medium or format, as long as you give appropriate credit to the original author(s) and the source, provide a link to the Creative Commons licence, and indicate if changes were made. The images or other third party material in this article are included in the article's Creative Commons licence, unless indicated otherwise in a credit line to the material. If material is not included in the article's Creative Commons licence and your intended use is not permitted by statutory regulation or exceeds the permitted use, you will need to obtain permission directly from the copyright holder. To view a copy of this licence, visit http://creativecommons.org/licenses/by/4.0/.

(c) The Author(s) 2021 